\title{
CT and MRI Techniques for Imaging Around Orthopedic Hardware
}

\section{CT- und MRT-Bildgebung bei orthopädischen Implantaten}

Authors

Thuy Duong Do ${ }^{1}$, Reto Sutter ${ }^{2}$, Stephan Skornitzke ${ }^{1}$, Marc-André Weber ${ }^{1}$

Affiliation

1 Department of Clinical Radiology, University of Heidelberg, Germany

2 Radiology, Uniklinik Balgrist, Zurich, Switzerland

Key words

metal artifact, artifact reduction, MRI, CT

received 30.11 .2016

accepted 25.07.2017

Bibliography

DOI https://doi.org/10.1055/s-0043-118127

Published online: 21.9.2017

Fortschr Röntgenstr 2018; 190: 31-41

(c) Georg Thieme Verlag KG, Stuttgart · New York

ISSN 1438-9029

Correspondence

Thuy Duong Do

Department of Clinical Radiology, University of Heidelberg, Im Neuenheimerfeld 110, 69120 Heidelberg, Germany

Tel.: ++ 49/62 21/56 6410

Fax: $++49 / 6221 / 565730$

thuyd_do@gmx.de

\section{ZUSAMMENFASSUNG}

Orthopädische Implantate verringern die Bildqualität in der Schnittbildgebung. Bei steigendem Einsatz von orthopädischen Implantaten in einer alternden Bevölkerung ist eine Metallartefaktreduktion von zunehmender Bedeutung. Im folgenden Review möchten wir einen Überblick über die wesentlichen Artefakte in der Computertomografie und Magnetresonanztomografie sowie die neuesten Standards zur Verbesserung der Bildqualität geben. Alle Schritte der Bildakquisition von Gerätewahl über Scanvorbereitungen und - parameter bis hin zur Bildverarbeitung beeinflussen das Ausmaß der Metallartefakte. Technische Fortschritte wie die Dual-energy-Computertomografie mit der Option der Virtuellen monochromatischen Bildgebung sowie neue Implantatmaterialien bieten weitere Möglichkeiten der Metallartefaktreduktion in CT und MRT. Dezidierte MetallartefaktSequenzen beinhalten Algorithmen zur Artefaktreduktion und zur Verbesserung der Bildqualität des umgebenden Gewebes und sind essenzielle Werkzeuge in der orthopä- dischen Bildgebung zur frühzeitigen Detektion von postoperativen Komplikationen.

\section{Kernaussagen:}

- Periprothetisches Weichteilgewebe können trotz Metallartefakte gut visualisiert werden

- Artefaktreduktion in der Computertomographie: Akquisitionsparameter, iterative Rekonstruktionen, Dual-energy CT und VMS

- Artefaktreduktion im MRT: Gerätewahl, Sequenzen, Akquisitionsparameter und MARS

\section{ABSTRACT}

Orthopedic hardware impairs image quality in cross-sectional imaging. With an increasing number of orthopedic implants in an aging population, the need to mitigate metal artifacts in computed tomography and magnetic resonance imaging is becoming increasingly relevant. This review provides an overview of the major artifacts in CT and MRI and state-ofthe-art solutions to improve image quality. All steps of image acquisition from device selection, scan preparations and parameters to image post-processing influence the magnitude of metal artifacts. Technological advances like dual-energy CT with the possibility of virtual monochromatic imaging (VMI) and new materials offer opportunities to further reduce artifacts in CT and MRI. Dedicated metal artifact reduction sequences contain algorithms to reduce artifacts and improve imaging of surrounding tissue and are essential tools in orthopedic imaging to detect postoperative complications in early stages.

\section{Key points}

- Tissues around orthopaedic hardware can still be well visualised despite metal artifacts.

- Artefact reduction in CT: acquisition parameters, iterative reconstruction, Dual-energy CT and VMI.

- Artefact reduction in MRI: choice of device, sequences, acquisition parameters and MARS

\section{Citation Format}

- Do TD, Sutter R, Skornitzke S et al. CT and MRI Techniques for Imaging Around Orthopedic Hardware. Fortschr Röntgenstr 2018; 190: 31-41 

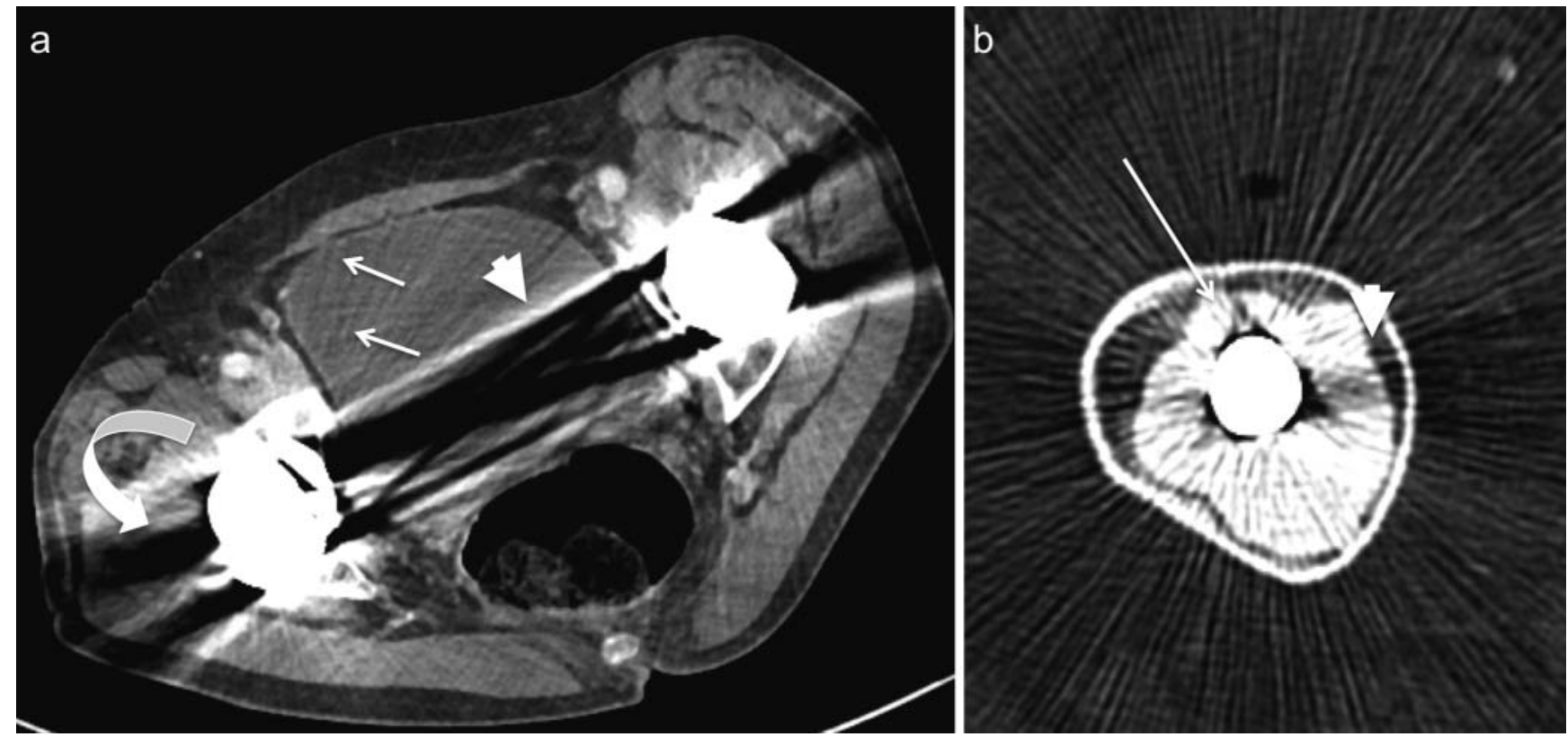

- Fig. 1 a Splay artifacts as radiating dark and bright streaks (arrows). Streak artifacts (arrowhead). Beam hardening artifacts (bowed arrow). b Non-linear partial volume effect with dark and white streaks connecting edges (arrow) and scatter artifact with dark shades around the metal (arrowhead).

- Abb. 1 a Splay-Artefakte als ausstrahlende schwarze und helle Streifen (Pfeil). Streifenartefakte (Pfeilköpfe). Aufhärtungsartefake (gebogener Pfeil). b Nicht-lineare Partialvolumeneffekte mit schwarzen und weißen kantenverbindenden Streifen- und Scatter-Artefakte mit dunklen Schatten um das Metallimplantat (Pfeilkopf)

\section{Introduction}

Cross-sectional imaging has become the fundamental basis of modern diagnosis, treatment planning and follow-up in many musculoskeletal diseases. However, orthopedic metal implants often impede the accurate evaluation of the region of interest in cross-sectional imaging. With an increase in life expectancy and improved durability of implants, more joint prostheses and other orthopedic hardware will be seen in the future. Orthopedic hardware is no longer an obstacle or contraindication for CT or for MRI. The radiologist's role includes providing recommendations for the best imaging modality for patients with orthopedic hardware and optimization of imaging protocols to reduce metal artifacts and making an accurate diagnosis based on the acquired images. In general, apart from CT and MRI, ultrasound should also be considered as a cost-effective mean to detect fluid collections adjacent to orthopedic hardware. Additionally, ultrasound can provide a guidance system to facilitate needle placement for fluid aspiration or intervention.

\section{Metal artifacts observed in computed tomography}

Metallic hardware influences image acquisition and reconstruction in computed tomography (CT) in several ways: Beam hardening, splay artifacts, scatter effects and non-linear partial volume effects along the edges of the hardware.
On the other hand, the extent of orthopedic hardware artifacts is related to the tube potential, tube current and reconstruction parameters. Alloy, size, geometry of the implants as well as the orientation of the implant relative to the gantry affect the magnitude of image artifacts [1].

Beam hardening artifacts are generated when the polychromatic spectrum of the X-ray beam is attenuated by high attenuation objects. Low energy photons are more easily deflected, resulting in photon starvation. As such, beam hardening occurs not only with metal implants but also with iodinated contrast agents and barium [2, 3]. Beam hardening artifacts typically appear as dark streaks and low attenuation penumbra around the high attenuation object ( $\vee$ Fig. 1a). Resulting streak artifacts mostly propagate along the projection axis of the greatest metal bulk. For example, the most severe metal artifacts in patients with bilateral hip implants present along the $x$-axis, since the attenuation of both implants due to photon starvation is summed up in the respective projection trajectories ( $\nabla$ Fig. 1a) [4].

Scatter artifacts also appear as dark and adjacent bright streaks in the image and are related to the Compton effect ( $\triangleright$ Fig. 1b). X-ray photons deviate from their original trajectory and generate signals in a different detector than the one in line with the original trajectory. The bigger the irradiated tissue volume, the more scatter artifacts can be observed. The scattered radiation also reduces the signal-to-noise ratio (SNR) and deteriorates image contrast [5].

Splay artifacts or windmill artifacts present as alternating radially oriented bright and dark bands, which are only found in helical multidetector $\mathrm{CT}$ but not in single-row detector $\mathrm{CT}$. The 
restricted width of the detector array elements and the helical acquisition result in an undersampling of the examined region in the z-axis. Thus, two detector rows are interpolated for reconstruction, causing artifacts especially at high contrast edges, e. g. along the rim of the hardware. Narrow window settings accentuate splay artifacts. Hardware with a rectangular cross-sectional shape such as a fixation plate will cause more artifacts than a radially symmetrical device ( $\triangleright$ Fig. 1a) [3].

Non-linear partial volume effects are produced by the averaging over the beam width and focal spot. The incidence of these effects is higher when the hardware is in an eccentric position or scans are acquired with broad collimation. They are generated when the hardware is not continuously irradiated by the rotating $\mathrm{X}$-ray tube and thus only part of the X-rays per rotation is being attenuated. They arise as dark and white streaks especially at sharp edges on the final images ( $\triangleright$ Fig. 1b) [2].

In hardware alloys with a high atomic number, metal artifacts are more pronounced. Stainless steel or cobalt chrome hardware produces the most artifacts, while titanium hardware produces the least $[6,7]$.

\section{Metal artifact reduction in computed tomography}

$\mathrm{CT}$ is an appropriate cross-sectional imaging method for postoperative imaging, even in the presence of orthopedic hardware, although hardening artifacts along metallic non-radiopaque materials may impair image quality in $\mathrm{CT}$. However, these can be overcome using recent advances in CT technology. Thus, CT plays an important role in the postoperative evaluation of patients who are suspected of having prosthesis-related problems such as aseptic loosening, infection, granulomatous particle disease, implant failure, malpositioning of components and periprosthetic fracture [4].

Sometimes it is possible and the easiest way to displace the hardware outside the region of interest, for example, in case of bilateral knee prosthesis, is to flex the contralateral knee to reduce metal artifacts in the knee of interest [1].

\section{$\mathrm{CT}$ acquisition parameters}

To mitigate metal artifacts, detector collimation and pitch should be decreased, whereas tube peak voltage and tube current should be increased. These measures might overcome photon starvation and beam hardening, but a reasonable trade-off has to be made between image quality and patient dose. Another limitation for increasing the tube voltage is a decreasing soft tissue contrast [8].

\section{Device equipment}

Scatter artifacts can be addressed by using an anti-scatter grid also known as collimators, which are installed in most CT scanners today. Scatter grids are parallel (one-dimensional) or crossed lamellas (two-dimensional) positioned between the individual detectors to absorb the scattered photons. X-ray absorbing materials like tungsten, lead, copper, molybdenum and tantalum can be used for scatter grids [9].
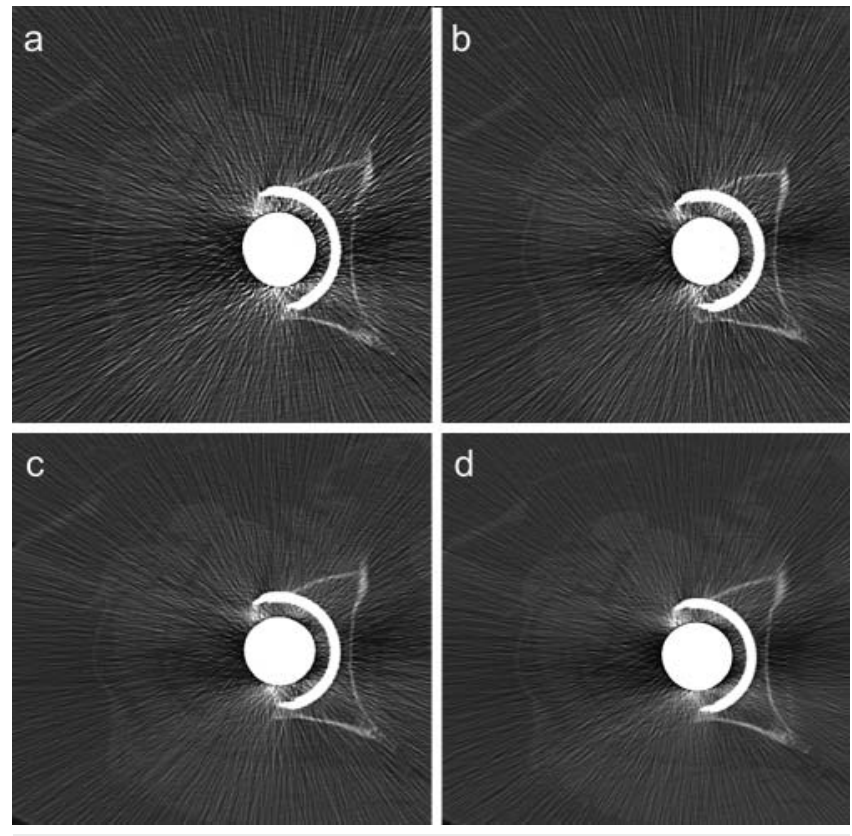

- Fig. 2 Different slice thickness reconstructions $0.75 \mathrm{~mm}$ a, $1.0 \mathrm{~mm} \mathrm{~b}, 2.0 \mathrm{~mm} \mathrm{c}$, and $4.0 \mathrm{~mm}$ d.

- Abb.2 Rekonstruktionen in unterschiedlichen Schichtdicken $0,75 \mathrm{~mm}$ a, $1,0 \mathrm{~mm}$ b, $2,0 \mathrm{~mm}$ c und $4,0 \mathrm{~mm}$ d.

\section{Post-processing}

The thinner the reconstructed slice thickness, the worse the splay artifacts become. They are decreased by thicker slice reconstruction and are essentially eliminated when the slice thickness is twice or greater than the width of the detector elements ( $\triangleright$ Fig. 2). A slice thickness of 1 to $2 \mathrm{~mm}$ is a possible compromise between partial volume effect and artifact reduction. This thickness applies to larger joints. For joints that require a high resolution like the wrist or ankle, increasing slice thickness is not recommended.

Splay artifacts can be further reduced by using a new technique involving a z-flying focal spot. The focal spot alternates between two positions along the z-axis periodically. Thus, the number of slice readouts is twice the real number of detector rows. This results in a larger scan volume, reduced primary layer collimation, and volumetric pixels [10].

Smoother reconstruction filters can also reduce metal artifacts and noise, for example a standard filter used for general abdomen imaging instead of a bone filter can be used. This, however, results in less detailed visualization with reduced spatial resolution.

Changing CT parameters and reconstruction filters is one possibility to diminish metal artifacts. Iterative reconstructions provide an additional means of minimizing calcium blooming and metal artifacts.

In addition to conventional iterative reconstruction algorithms, there are special post-processing algorithms focused on minimizing metal artifacts like O-MAR (Philips), iMAR (Siemens) and MAR (GE), which are also known as projection-based artifact correction. Their common principle is based on a combination of corrected iterative data and raw data (normalized metal artifact reduc- 


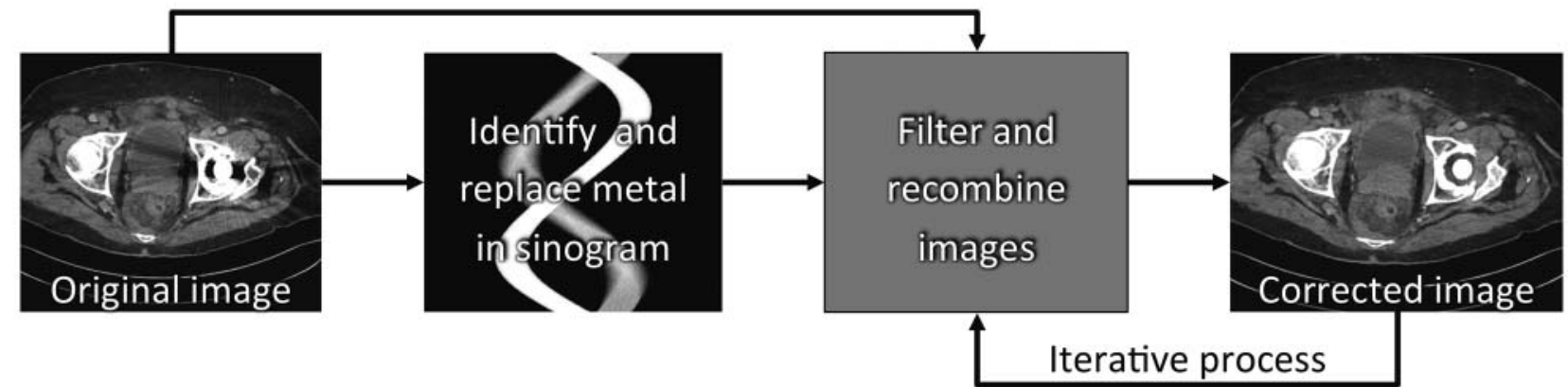

- Fig. 3 Iterative metal artifact reduction: Projection data containing metal is identified and replaced in the sinogram by forward projection or inpainting. The corrected sinogram is used to reconstruct a corrected image that is filtered and recombined with the original image in an iterative process.

- Abb. 3 Iterative Rekonstruktionen zur Metallartefaktreduktion: Projektionsdaten des Metallimplantats werden identifiziert und im Sinogramm durch eine „Forward projection“ oder „Inpainting“ ersetzt. Das korrigierte Sinogramm ist die neue Grundlage für die Rekonstruktion des korrigierten Bildes, das gefiltert und mit dem Originalbild in einem iterativen Prozess kombiniert wird.

tion and frequency split metal artifact reduction). The metal implant is removed from the original image by multi-threshold metal segmentation. Linear interpolation is performed on the sinogram and the inpainted sinogram is combined with the original data to create the corrected image. This filtering and mixing step is performed repeatedly to reduce blurring of the adjacent anatomic structures ( $\triangleright$ Fig. 3 ) [11, 12]. The iterative frequency split-normalized algorithm has been shown to improve the visibility of tissues adjacent to and distant from the implant and is superior in comparison to conventional reconstruction with filtered back projection and metal artifact reduction with linear interpola-

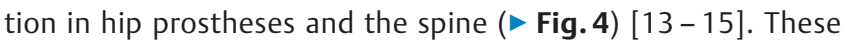
post-processing techniques are computationally intensive but the processing time takes less than 1 minute. Care has to be taken, however, to identify new artifacts induced by these projection-based algorithms, especially areas of pseudo-osteolysis that commonly appear at the bone-metal interface $[9,16]$. The radiologist can avoid making the false-positive diagnosis of implant loosening or an osteolytic bone lesion only by comparing the projection-based corrected images side-by-side with the standard CT reconstructions ( $\mathbf{F i g} . \mathbf{5}$ ). Thus, it is wise to additionally transfer these standard reconstructions to the local PACS (picture archiving and communication system).

\section{Dual-energy methods}

With dual-energy (DE) CT, two datasets are acquired from the same anatomic region at two different tube potentials, usually $140 \mathrm{kV}_{\mathrm{p}}$ and $80 \mathrm{kV}_{\mathrm{p}}$. This can be achieved either by using a singlesource with fast voltage switching, dual-source and dual-energy $X$-ray tubes or a single-source with dual detector layers. Differences in material composition can be distinguished based on theanalysis of energy-dependent photon absorption of different materials. Virtual monochromatic spectral images (VMS) are synthesized from dual-energy CT data and a new image looks as if the $\mathrm{X}$-ray tube produced $\mathrm{X}$-ray photons at only one energy level from $40-190 \mathrm{keV}$. The optimal energy level keV is variable, depending on the region of interest. Prosthetic loosening is best seen at $140 \mathrm{keV}$. Images at 70 or $80 \mathrm{keV}$ allow for better visualization of fluid collection and soft tissues close to the prosthesis ( $\triangleright$ Fig. 6) [17 - 19]. In addition to the dual-energy method, vendor-specific iterative metal artifact reduction software can be applied. There have been a lot of considerations and discussion on radiation dose in dual-energy CT. Most studies have been performed on dual-source $C T$ and have not shown an increased radiation dose $[11,12,20,21]$. Data on DE CT with fast-switching kilovoltage are ambiguous. If contrast-enhanced imaging is needed, DE CT is feasible for dose reduction as native scans can be omitted and virtual non-enhanced data can be generated [22]. Dual energy scans have the potential to correct for beam hardening, but cannot reduce scatter artifacts.

\section{New hardware materials}

Carbon alloys are not only used in modern space technology and in car racing, e.g. Formula 1. These implants consist of carbon fibers with reinforced polyetheretherketone (carbon/PEEK). They also have proven high performance properties in orthopedic implants on account of their high fatigue strength, low weight and improved load transfer to the bone [23]. Thus, stress shielding is reduced and bone healing is supported. Moreover, the material is radiolucent and non-magnetizable und thus minimizes artifacts on X-rays, CT and MRI scans ( $\triangleright$ Fig. 7) [24]. Hence, carbon/PEEK implants provide better visualization of surrounding tissues, when compared to frequently used metals like stainless steel, cobalt-chrome ( $\mathrm{Co}-\mathrm{Cr}$ ) or tantalum. Another alloy, which produces fewer artifacts, is titanium.

\section{Current research}

The feasibility of new metal artifact algorithms as well as dual energy application for metal artifact reduction has been tested for different types of implants [25 - 27]. Further studies are currently focusing on showing an enormous dose reduction in CT using metal artifact reduction software and virtual monochro- 

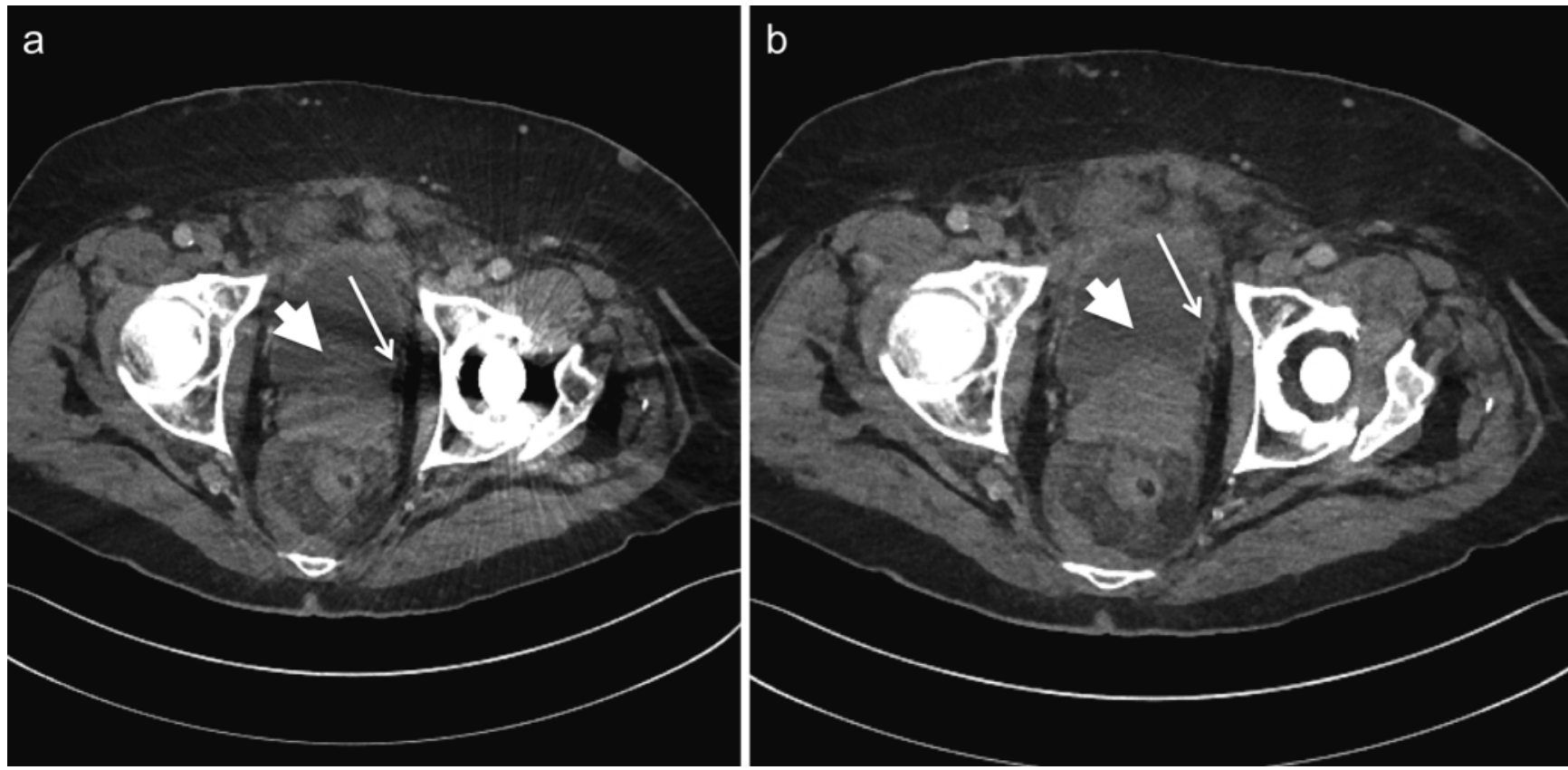

- Fig. 4 Filtered back projection a vs. iterative reconstructions 3 rd generation $\mathbf{b}$ with iMAR. With filtered back projection, metal artifacts impede the delineation of lymphoma involvement of the dorsal bladder wall (arrowhead) and the evaluation of the lateral pelvic wall (arrow).

- Abb.4 Gefilterte Rückprojektionen a vs. iterative Rekonstruktionen der 3. Generation b mit iMAR. Bei der gefilterten Rückprojektion verhindern Metallartefakte das Erkennen der Lymphominfiltration der dorsalen Harnblasenwand (Pfeilkopf) und die Beurteilung der lateralen Beckenwand (Pfeil).
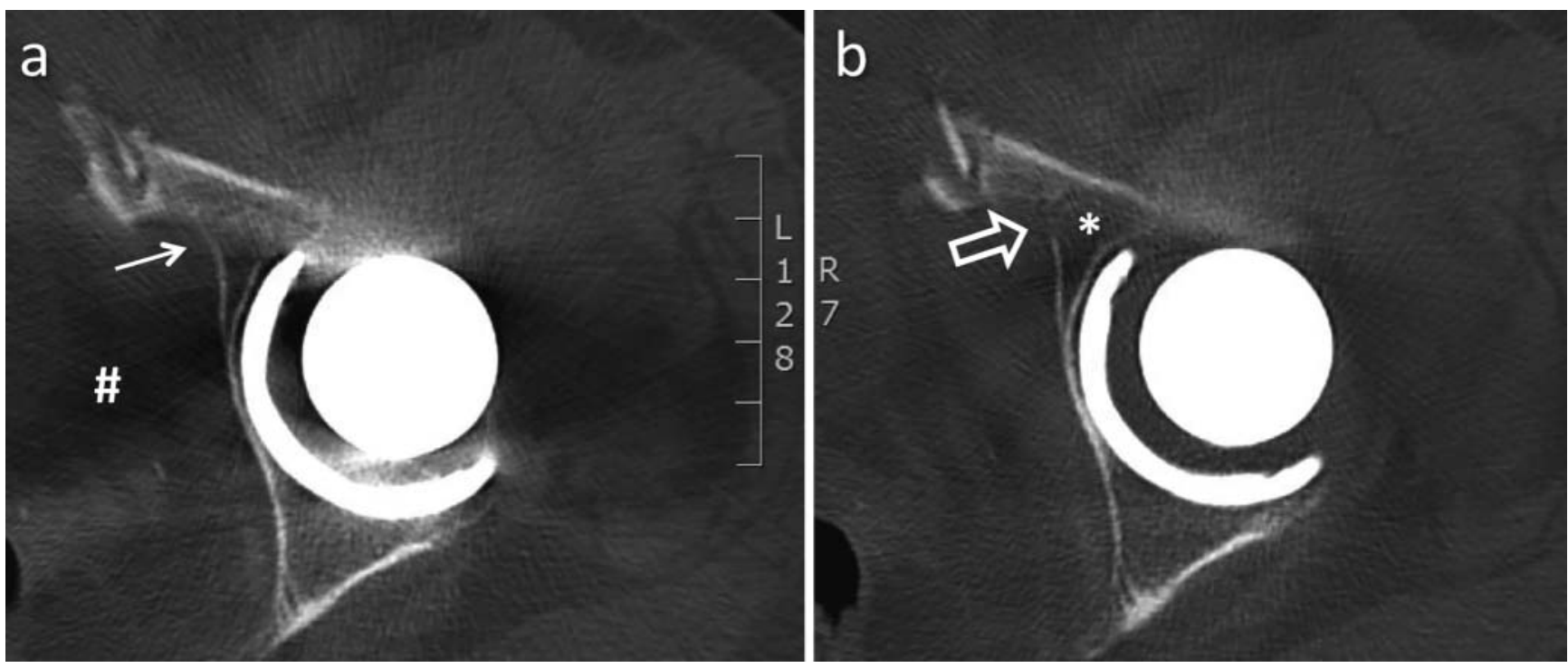

- Fig. 5 Projection-based algorithms for reducing CT metal artifacts (e. g. O-MAR, iMAR) may induce pseudoosteolysis adjacent to the metal. a Transverse CT image of total hip arthroplasty with standard filtered back projection shows normal cortical bone medial to the prosthesis cup (thin arrow). Note beam hardening artifacts (\#) overlaying the pelvic soft tissues. b Transverse CT image at the same level with O-MAR features marked overall reduction of metal artifacts, but shows pseudoosteolysis (asterisk) anterior to the prosthesis cup, causing a false-positive cortical destruction (outline arrow).

- Abb.5 Projektionsbasierte Algorithmen zur CT Metallartefaktreduktion (z. B. O-MAR, iMAR) können Pseudoosteolysen angrenzend an das Implantat vortäuschen. a Transversale CT einer Hüfttotalendoprothese mit gefilterter Rückprojektion zeigt einen normalen kortikalen Knochen medial der Gelenkpfanne (dünner Pfeil). Aufhärtungsartefakte (\#) überlagern Beckenweichteile. b Transversale CT auf derselben Höhe mit O-MAR bietet eine umfassende Metallartefaktreduktion, zeigt jedoch auch eine Pseudoosteolyse (Stern) anterior der Gelenkpfanne, welche eine falschpositive kortikale Destruktion (Vektorpfeil) vortäuscht. 

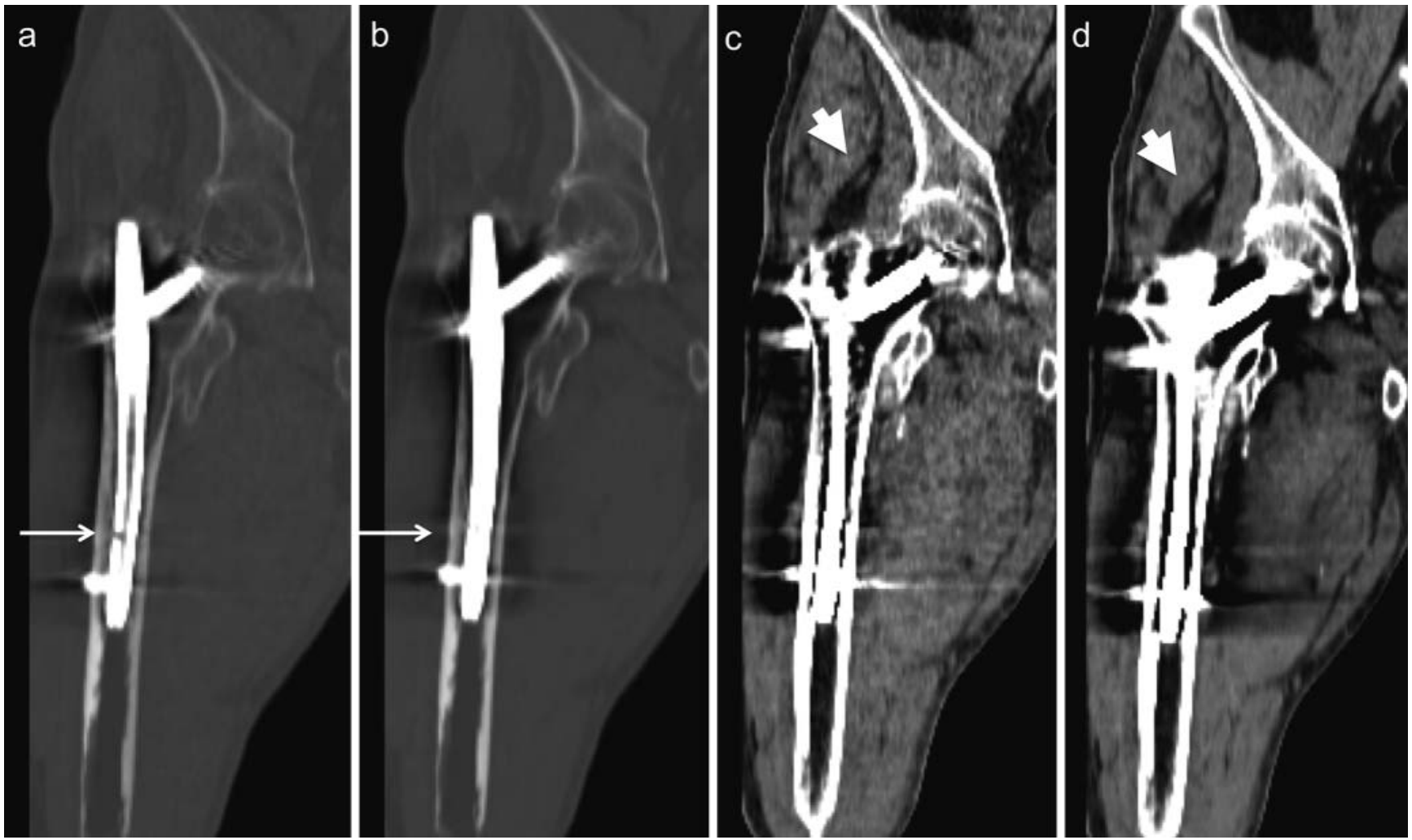

- Fig. 6 Virtual monochromatic spectral image reconstructions at different keV. Surrounding bone structures and implants (arrows) are better seen at $140 \mathrm{keV}$ a than $80 \mathrm{keV} \mathbf{b}$ and soft tissues (arrow head) at $80 \mathrm{keV} \mathbf{c}$ than at $140 \mathrm{keV} \mathbf{d}$.

- Abb. 6 Virtuell monochromatische spektrale Bildrekonstruktionen bei unterschiedlichen keV. Der umgebende Knochen und die Implantate (Pfeile) werden bei $140 \mathrm{keV}$ a besser als bei $80 \mathrm{keV}$ b, die Weichteile (Pfeilspitzen) bei $80 \mathrm{keV}$ c besser als bei $140 \mathrm{keV}$ d dargestellt.

matic imaging in comparison to iterative reconstruction and FBP alone [28]. Efforts have been made to objectively evaluate different commercial metal artifact reduction algorithms (European Congress of Radiology 2017, Comparison of metal artefact reduction in dual- and single-source CT: a vertebra phantom study; Metal artefact reduction in CT: objective evaluation of three commercial algorithms). The use of carbon/Peek implants has been shown to minimize artifacts, but so far studies have only been performed on human cadavers [29].

\section{Metal artifact reduction in magnetic reso- nance imaging}

The single steps of an MR examination can be simplistically summarized as follows: The patient is placed in a homogenous static magnetic field. Then a radio wave (radiofrequency pulse) is sent in and turned off again. After that, the patient emits a signal, which is received and used for reconstruction of the MR image. Radiofrequency coils are necessary to send in the RF pulse and to excite the net magnetization induced by the precessing protons, and to receive the resulting MR signal. The spatial information is encoded by three gradient coils superimposed on the main magnetic field. Metal implants can cause electrical conduction and induce currents. These new currents in turn can build up a new magnetic field and generate a magnetic distortion. The distortions occur not only within a plane, so-called "in-plane artifacts", but also beyond the intended slice, termed "through-plane artifacts", thereby distorting the $3 \mathrm{D}$ structure of the image slice itself. Moreover, the dephasing of the protons is accelerated in the presence of metal. Inhomogeneous magnetic fields induce false spatial readouts leading to geometric distortion, signal loss and pile-up effects as well as failure of homogeneous fat suppression [30].

While the number of current metallic implants with ferromagnetic properties is decreasing, many implant types still contain ferromagnetic components. An effective MRI in patients with joint replacement and other metallic implants therefore has to include sequences with a powerful metal artifact reduction sequence package. With the use of modern artifact reduction sequences, MRI has evolved as the modality of choice for the imaging of the surrounding soft tissues, bone marrow edema, postoperative hematoma, periprosthetic masses and synovitis.

\section{Hardware alloy}

In MRI, the alloy of the implants also determines the extent of artifacts and depends on the susceptibility of the hardware ( $\mathrm{X}$ ). Ferromagnetic hardware $(x>300 \mathrm{ppm})$ causes severe artifacts in comparison to paramagnetic materials $(0<x<300$ ppm), e. $g$. 

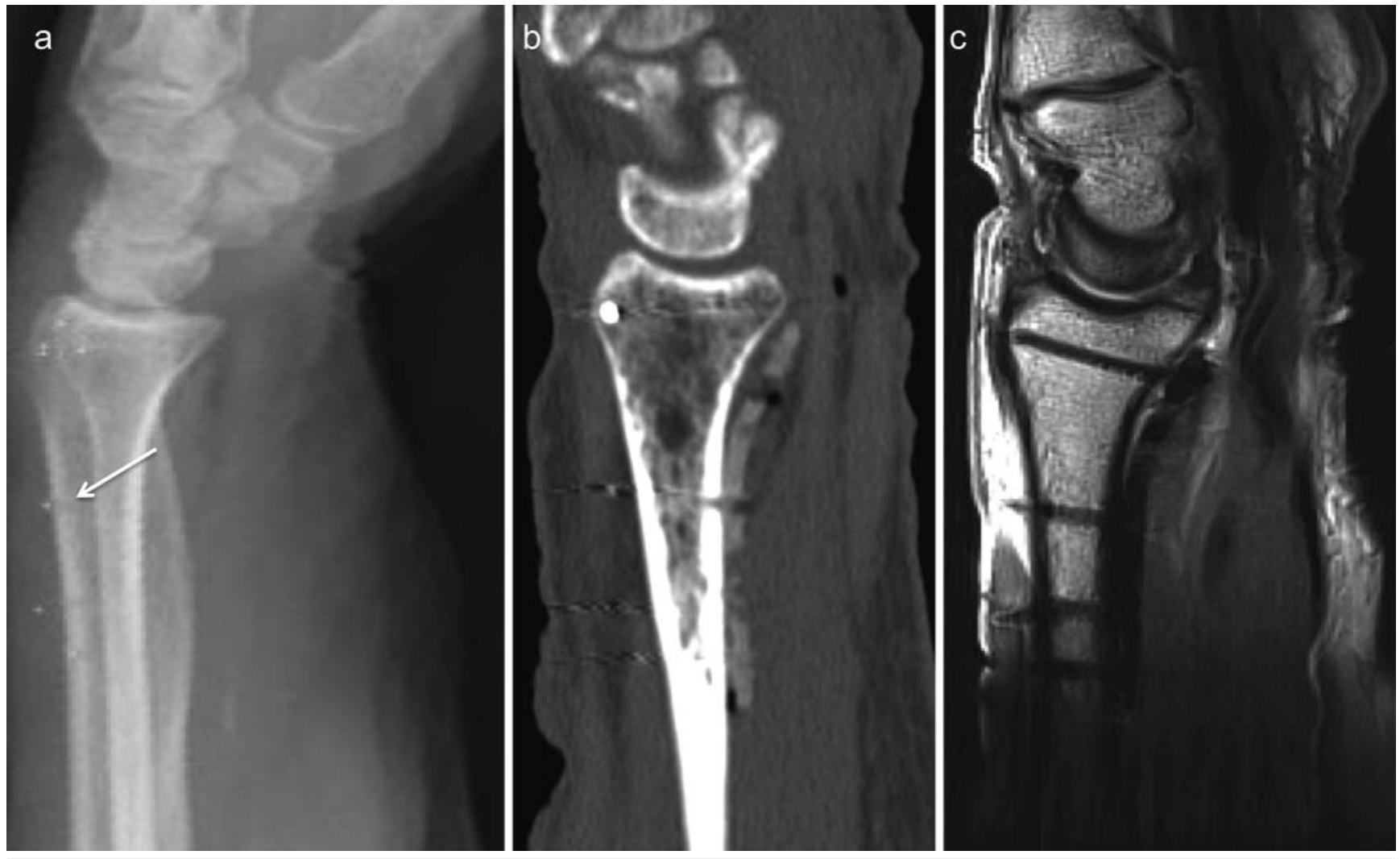

- Fig.7 Angle-stable osteosynthesis of carbon-PEEK composite material with minimal artifacts and with markers (arrows) dorsal to the radius in the projection radiograph a, CT b and sagittal T2-weighted MRI c.

- Abb.7 Winkelstabile Carbon-PEEK-Osteosyntheseplatte mit minimalen Artefakten und Markern dorsal des Radius im Röntgen a, CT b und in der sagittalen T2-gewichteten MRT c.

stainless steel $>$ cobalt chrome $>$ nickel $>$ tantalum $>$ oxidized zirconium [1].

\section{MR device}

If scanners with different field strengths are available at a facility, we strongly recommend performing imaging on scanners with lower static field strengths $\mathrm{B}_{0}$, e. g. 1.5 T rather than $3 \mathrm{~T}$ ( $\triangleright$ Fig. 8). With a higher static magnetic field strength, the extent of metal artifacts rises, as the implants' electrical conductivity increases. This effect is more prominent, especially with increased RF frequencies [31].

\section{MR parameters}

Increasing receiver bandwidth (rBW) reduces in-plane displacement and is a simple but powerful basic tool for reducing metal artifacts, especially in non-fat-suppressed turbo-spin echo sequences [32]. The SNR calculation is indirectly proportional to the root of the bandwidth. Thus, an increase in bandwidth means a lower SNR.

Thin sections should be acquired to achieve low through-plane displacement by decreasing the voxel size and reducing intra-voxel dephasing [31], though this reduces the SNR and is concomitant with a longer examination time as the number of averages needs to be raised to obtain a sufficient SNR.
Moderate echo times still provide fluid sensitivity, though not strictly T2-weighted. For 1.5 T, an echo time of less than $100 \mathrm{~ms}$, preferably $30-40 \mathrm{~ms}$, is recommended, as it provides less time for spin dephasing. With $3 \mathrm{D}$ ultra-short TE, even minimal echo times of $60 \mu$ s at $1.5 \mathrm{~T}$ are possible [33].

Magnetic field inhomogeneity due to orthopedic hardware causes erroneous mapping in frequency and phase encoding direction. The misregistration of spins is more conspicuous in the frequency encoding direction than in the phase encoding direction. Therefore, the frequency encoding direction can be changed, e. g. anterior to posterior, to minimize artifact in the region of interest. The frequency encoding matrix should be increased to 512 with a corresponding adaptation of the phase encoding axis to achieve the smallest voxel size [31]. However, small voxels and increased receiver bandwidth are associated with a decreased SNR, which in turn can be alleviated with an increasing number of excitations. We recommend increasing the receiver bandwidth for STIR (short tau inversion recovery) sequences to at least $150 \mathrm{~Hz} /$ pixel for $1.5 \mathrm{~T}$ and $246 \mathrm{~Hz} /$ pixel for $3 \mathrm{~T}$, if possible even higher.

2D- and 3D-gradient echo sequences (GE) are more susceptible to artifacts than spin echo sequences (SE), as the spin-spin dephasing takes place faster in GE than SE sequences. Fast or turbo spin-echo sequences should be preferred, as they have higher 

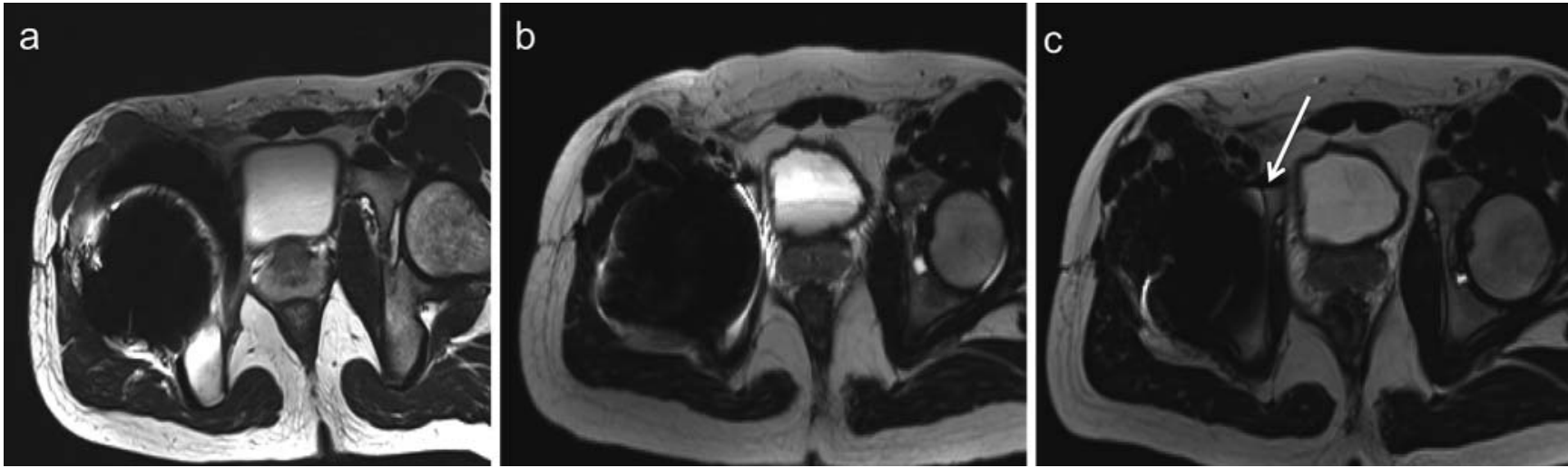

- Fig. 8 T2-weighted images of a patient with hip arthroplasty and aseptic lymphocyte-dominated vasculitis-associated lesion (ALVAL) (arrow) at $3 \mathrm{~T} \mathbf{a}, 1.5 \mathrm{~T} \mathbf{b}$ and $1.5 \mathrm{~T}$ with SEMAC and VAT $\mathbf{c}$.

Abb. 8 T2-gewichtete Bilder eines Patienten mit Hüfttotalendoprothese und Pseudotumor (Pfeil) bei 3 T a, 1,5T b und 1,5T mit SEMAC und VAT c.

signal efficiency while using the $180^{\circ}$ refocusing pulse to compensate the magnetic field inhomogeneities. The number of echoes that is acquired after every excitation pulse is referred to as the echo train length and is equivalent to the speed gain of the turbo spin echo in comparison to a single spin echo. The inter-echo spacing should be as short as possible to be able to acquire a large number of echoes before the signal deteriorates due to T2 signal decay.

\section{Fat suppression}

Fat suppression for MRI is a sensitive tool for detecting edema, fluid collections and contrast enhancement, but the presence of hardware within the magnetic field results in insufficient or inhomogeneous fat suppression.

If fat suppression is needed, inversion recovery fat suppression (STIR) should be used instead of frequency-selective fat suppression. Inversion-recovery sequences provide more homogeneous fat suppression than frequency-selective fat suppression based on chemical shift, even though the fat suppression is not lipidspecific and therefore tissues with similar T1 are suppressed as well. If the inversion recovery also includes an inversion pulse with an increased bandwidth that is matched to the increased receiver bandwidth, the fat suppression is even more stable in the presence of metal implants [32]. Another option for fat suppression is the DIXON technique. T1-weighted images in in- and opposed-phase are acquired and can be processed by subtraction to yield additional images that show either the water or fat content of the tissue ( $\vee$ Fig. 9). The image showing the water content is also a fat-suppressed image that is more resistant to metal artifacts than spectral fat suppression. Although the STIR sequence is superior with respect to fat suppression immediate to the metal implant in comparison to the DIXON technique, the DIXON technique can also be used for post-contrast imaging. In case of contrast-enhanced images, it is also recommended to acquire a T1weighted sequence pre- and post-contrast and then to perform a subtraction image to delineate areas of contrast enhancement [34]. For the calculation of a subtraction image, it is obligatory that the pre- and post-contrast images are identical, i. e. have the same slice thickness, slice numbers and center.

\section{New metal artifact reduction sequence}

More recent metal artifact reduction sequences (MARS) reduce the in-plane and through-plane effects of artifacts. A possibility to reduce in-plane misregistration is to add "view angle tilting" (VAT) in the readout encoding direction. It is an additional compensatory gradient during the readout in the slice encoding direction, as it is assumed that there is a constant inaccuracy of the readout direction. Thus, the spins are read out at an angulated view. Cho et al. first proposed viewing the slice at a shifted angle [35]. It can cause some blurring, though, which can be countered by using thin sections and large bandwidth.

Other MARS techniques are the "multi-acquisition variable-resonance image combination" technique (MAVRIC) and "slice encoding for metal artifact correction" (SEMAC). In the presence of metal hardware, the protons of the same slice no longer spin at the same Larmor frequency. MAVRIC obtains images by multiple acquisitions of data sets at different frequencies to correct for dispersion of the spins [36]. These data sets are remerged by a sum of squares algorithm to identify the artifacts and eliminate them within a plane.

In contrast to MAVRIC, SEMAC uses one frequency and switch on an additional phase-encoding gradient perpendicular to the $z$-axis before the readout and sums up the protons in the same phase and thus minimizes the through-plane displacement [37].

SEMAC is usually combined with VAT to diminish in-plane artifacts ( $\triangleright$ Fig. 10). With the recent development of ultrafast TE sequences and spectroscopic sequences like the "sweep imaging with Fourier transformation" (SWIFT), these might be used for hardware imaging as they are not susceptible to magnetic inhomogeneities [38].

\section{Current research}

The application of ultrafast TE sequences in combination with MARS has shown significant metal artifact reduction in knee ima- 

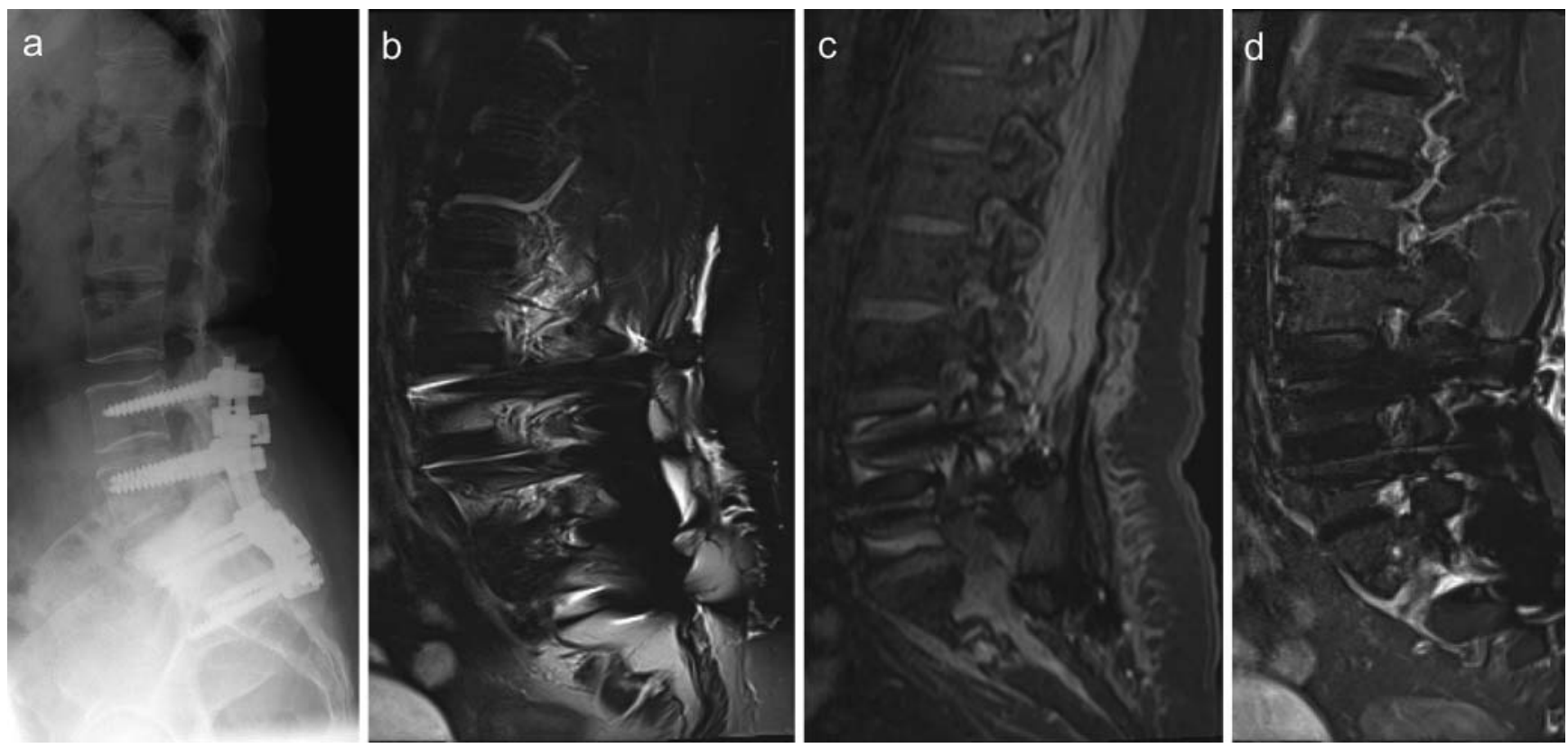

- Fig. 9 Female patient with plasmacytoma IgA type after radiation therapy with fatty transformation of the bone marrow L4 - S2 and dorsal spondylodesis on $\mathrm{X}$-ray a. Pronounced artifacts with T2w frequency selective fat suppression $\mathbf{b}$. Fewer metal artifacts but inhomogeneous fat suppression with DIXON sequence $\mathbf{c}$. Diminutive artifacts with sufficient and homogeneous fat suppression with STIR $\mathbf{d}$.

- Abb.9 Patientin mit einem Plasmozytom vom IgA-Typ, Zustand nach Bestrahlungstherapie mit fettiger Knochenmarkstransformation L4 - S2 und dorsaler Spondylodese im Röntgen a. Ausgeprägte Artefakte in der T2-gewichteten Frequenz-selektiven Fettsuppression b. Weniger Metallartefakte aber inhomogene Fettsuppression in der DIXON-Sequenz c. Geringe Artefakte mit guter und homogener Fettsuppression in der T2-STIR d.

ging [39], but has a long acquisition time und post-processing time. Recent research aims at reducing the acquisition time of MARS techniques by undersampling incoherent k-space and iterative reconstruction methods with equivalent metal artifact reduction to SEMAC sequences [40]. However, when using the MARS sequence, the hardware alloy still influences the extent of metal artifacts. A weak SEMAC-VAT with 7 slice-encoding steps does not seem to sufficiently reduce metal artifacts for all orthopedic implants, but only for titanium and oxidized zirconium prosthesis. A higher number of slice-encoding steps (11 - 15 steps) is required for stainless steel and cobalt-chromium-molybdenum [41].

\section{Ultrasound in patients with metal implants}

The radiologist may consider ultrasound as a cost-effective alternative with high availability to detect fluid collections, hematoma or pseudotumors adjacent to orthopedic hardware [42]. However, ultrasound has a lower resolution und reduced depth penetration, and areas beyond the metal implants are obscured by extinctions. Another disadvantage is the dependence on the experience of the examiner. It has been reported that ultrasound has a superior sensitivity to MRI in the detection of pseudotumors (100\% vs. $92 \%$ ) with MRI missing small pseudotumors. Ultrasound shows inferior specificity in comparison with MRI (96\% vs. $100 \%$ ) [43, 44].
Therefore, some centers suggest ultrasonography as a screening tool followed by MRI evaluation, especially for visualization of the posterior hip, multiple lesions and three-dimensional delineation of the lesion.

\section{Summary}

CT and MRI are complementary modalities for dedicated imaging in the presence of orthopedic hardware. Orthopedic hardware should not be considered to be an obstacle or contraindication for CT and MR imaging. The hardware alloy, its geometry and orientation all affect the magnitude of image artifacts. CT image artifacts are related to incomplete $\mathrm{X}$-ray projection data resulting in streaks. Modern techniques of reducing metal artifacts include iterative reconstruction $\mathrm{CT}$ techniques, which can be used on conventional single-energy acquisition, and dual-energy $C T$, as well as MARS techniques in MRI. If MARS techniques are not available, imaging at low field strengths, a thin slice thickness, and spin echo sequences should be preferred. STIR, DIXON, and subtraction techniques provide better fat suppression than frequencyselected fat suppression in the presence of metal hardware. If in the future carbon fibers instead of metal alloys are used more often for orthopedic hardware, this may allow for a drastic reduction in residual metal artifacts in radiological imaging of orthopedic patients. 


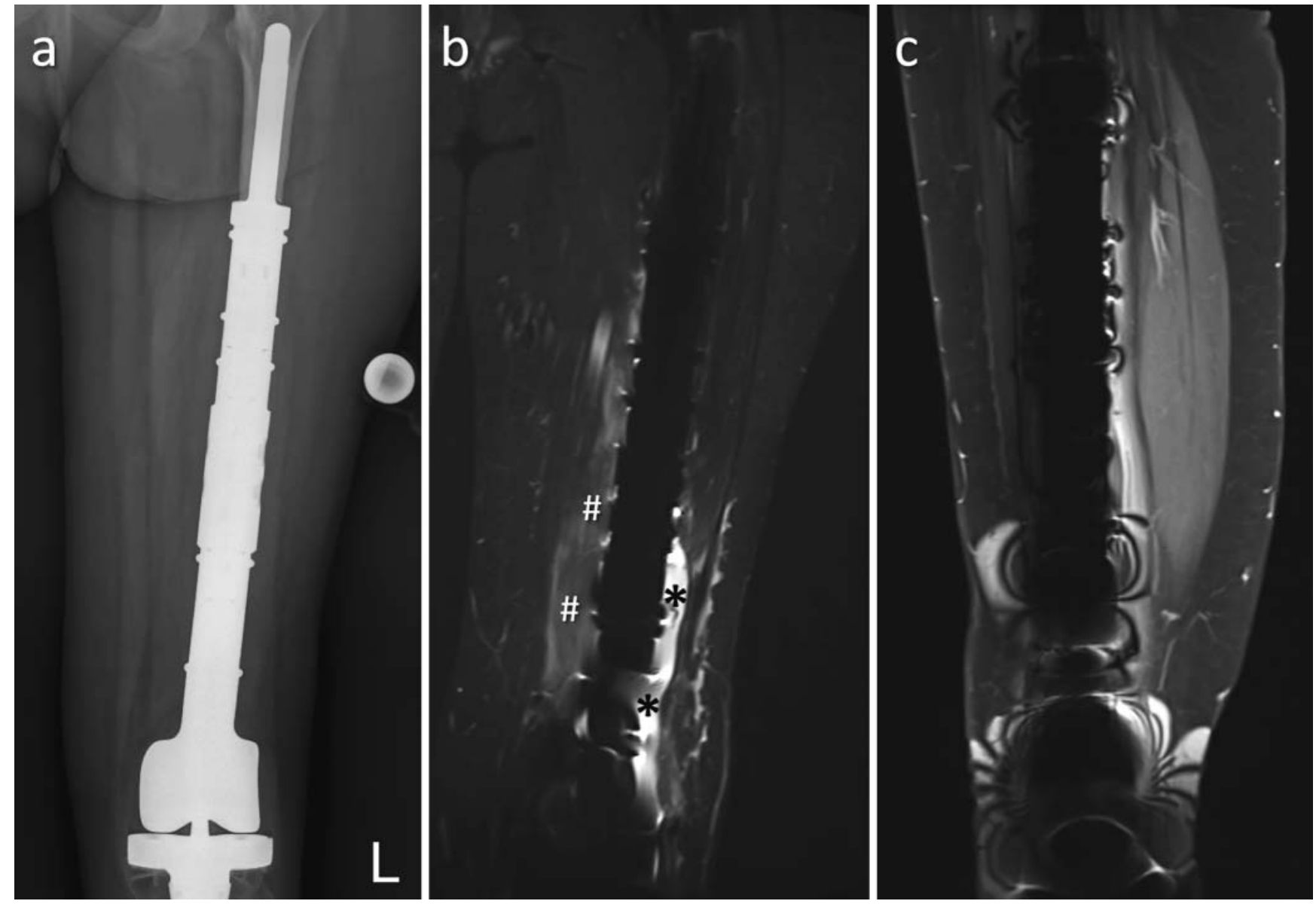

- Fig. 10 Patient with tumor prosthesis of the left femur and knee shown on a radiograph and MRI. b The coronal STIR WARP image with optimized inversion pulse shows a stable fat saturation and depicts muscle edema (\#), as well as periprosthetic fluid collection (asterisks). c The sagittal DIXON image (water image) is hampered by residual artifacts overlaying both the muscle edema and the periprosthetic fluid.

- Abb.10 Patient mit Tumorprothese im linken Femur und Knie im Röntgen a und MRT. b Das koronale STIR-WARP-Bild mit optimiertem Inversionspuls weist eine stabile Fettsättigung auf und stellt Muskelödem (\#) sowie die periprothetische Flüssigkeitskollektionen dar. c Das sagittale wassergewichtete DIXON-Bild wird durch residuelle Artefakte so stark beeinträchtigt, dass das Muskelödem und die periprothetische Flüssigkeitskollektion nicht erkennbar sind.

\section{Conflict of Interest}

The authors declare that they have no conflict of interest.

\section{References}

[1] Buckwalter KA, Lin C, Ford JM. Managing postoperative artifacts on computed tomography and magnetic resonance imaging. Semin Musculoskelet Radiol 2011; 15: 309-319

[2] Barrett JF, Keat N. Artifacts in CT: recognition and avoidance. Radiographics 2004; 24: 1679-1691

[3] Boas FE, Fleischmann D. CT artifacts: causes and reduction techniques. Imaging in Medicine 2012; 4: 229-240

[4] De Man B, Nuyts J, Dupont P et al. Metal streak artifacts in X-ray computed tomography: a simulation study. In: Nuclear Science Symposium, 1998 Conference Record 1998 IEEE. IEEE; 1998: 1860 - 1865

[5] Engel KJ, Herrmann C, Zeitler G. X-ray scattering in single- and dualsource CT. Med Phys 2008; 35: 318-332
[6] Haramati N, Staron RB, Mazel-Sperling K et al. CT scans through metal scanning technique versus hardware composition. Comput Med Imaging Graph 1994; 18: 429-434

[7] Wang JC, Yu WD, Sandhu HS et al. A comparison of magnetic resonance and computed tomographic image quality after the implantation of tantalum and titanium spinal instrumentation. Spine (Phila Pa 1976) 1998; $23: 1684-1688$

[8] Douglas-Akinwande AC, Buckwalter KA, Rydberg J et al. Multichannel CT: evaluating the spine in postoperative patients with orthopedic hardware. Radiographics 2006; 26 (Suppl. 1): S97-S110

[9] Vogtmeier G, Dorscheid R, Engel KJ et al. Two-dimensional anti-scatter grids for computed tomography detectors. In: Medical imaging: International Society for Optics and Photonics.2008. 691359-691359691311

[10] Stiller W. Principles of multidetector-row computed tomography : part 1. Technical design and physicotechnical principles. Radiologe 2011; 51: 625-637 quiz 638-629

[11] Meyer E, Raupach R, Lell M et al. Frequency split metal artifact reduction (FSMAR) in computed tomography. Med Phys 2012; 39: 1904-1916

[12] Healthcare P. Metal Artifact Reduction for Orthopedic Implants (O-MAR). Andover, Massachusetts: White Paper, Philips CT Clinical Science. 2012 
[13] Morsbach F, Bickelhaupt S, Wanner GA et al. Reduction of metal artifacts from hip prostheses on CT images of the pelvis: value of iterative reconstructions. Radiology 2013; 268: 237 -244

[14] Kotsenas AL, Michalak G], DeLone DR et al. CT Metal Artifact Reduction in the Spine: Can an Iterative Reconstruction Technique Improve Visualization? American journal of neuroradiology 2015; 36: 2184-2190

[15] Geyer LL, Schoepf UJ, Meinel FG et al. State of the Art: Iterative CT Reconstruction Techniques. Radiology 2015; 276: 339-357

[16] Malan DF, Botha CP, Kraaij G et al. Measuring femoral lesions despite CT metal artefacts: a cadaveric study. Skeletal Radiol 2012; 41: $547-555$

[17] Pessis E, Campagna R, Sverzut JM et al. Virtual monochromatic spectral imaging with fast kilovoltage switching: reduction of metal artifacts at CT. Radiographics 2013; 33: $573-583$

[18] Matsumoto K, Jinzaki M, Tanami Y et al. Virtual monochromatic spectral imaging with fast kilovoltage switching: improved image quality as compared with that obtained with conventional 120-kVp CT. Radiology 2011; 259: $257-262$

[19] Coupal TM, Mallinson PI, McLaughlin P et al. Peering through the glare: using dual-energy CT to overcome the problem of metal artefacts in bone radiology. Skeletal Radiol 2014; 43: 567-575

[20] Schenzle JC, Sommer WH, Neumaier K et al. Dual energy CT of the chest: how about the dose? Invest Radiol 2010; 45: 347- 353

[21] Henzler T, Fink C, Schoenberg SO et al. Dual-energy CT: radiation dose aspects. Am J Roentgenol 2012; 199: S16-S25

[22] Graser A, Johnson TR, Hecht EM et al. Dual-energy CT in patients suspected of having renal masses: can virtual nonenhanced images replace true nonenhanced images? Radiology 2009; 252: 433-440

[23] Ponnappan RK, Serhan H, Zarda B et al. Biomechanical evaluation and comparison of polyetheretherketone rod system to traditional titanium rod fixation. The Spine Journal 2009; 9: 263-267

[24] Zimel MN, Hwang S, Riedel ER et al. Carbon fiber intramedullary nails reduce artifact in postoperative advanced imaging. Skeletal Radiol 2015; 44: $1317-1325$

[25] Aissa J, Thomas C, Sawicki LM et al. Iterative metal artefact reduction in CT: can dedicated algorithms improve image quality after spinal instrumentation? Clin Radiol 2017; 72: 428 e427 - 428 e412

[26] Weiss ], Schabel C, Bongers M et al. Impact of iterative metal artifact reduction on diagnostic image quality in patients with dental hardware. Acta Radiol 2017; 58: 279-285

[27] Bongers MN, Schabel C, Thomas C et al. Comparison and Combination of Dual-Energy- and Iterative-Based Metal Artefact Reduction on Hip Prosthesis and Dental Implants. PLoS One 2015; 10: e0143584

[28] Wellenberg RH, Boomsma MF, van Osch JA et al. Low-dose CT imaging of a total hip arthroplasty phantom using model-based iterative reconstruction and orthopedic metal artifact reduction. Skeletal Radiol 2017; 46: $623-632$

[29] de Jong J], Lataster A, van Rietbergen B et al. Distal radius plate of CFRPEEK has minimal effect compared to titanium plates on bone para- meters in high-resolution peripheral quantitative computed tomography: a pilot study. BMC Med Imaging 2017; 17: 18

[30] Hargreaves BA, Worters PW, Pauly KB et al. Metal-induced artifacts in MRI. Am J Roentgenol 2011; 197: 547 - 555

[31] Graf H, Lauer UA, Berger A et al. RF artifacts caused by metallic implants or instruments which get more prominent at $3 \mathrm{~T}$ : an in vitro study. Magn Reson Imaging 2005; 23: 493 - 499

[32] Ulbrich EJ, Sutter R, Aguiar RF et al. STIR sequence with increased receiver bandwidth of the inversion pulse for reduction of metallic artifacts. Am J Roentgenol 2012; 199: W735-W742

[33] Koch KM, Hargreaves BA, Pauly KB et al. Magnetic resonance imaging near metal implants. J Magn Reson Imaging 2010; 32: 773 - 787

[34] Muller GM, Mansson S, Muller MF et al. MR imaging with metal artifactreducing sequences and gadolinium contrast agent in a case-control study of periprosthetic abnormalities in patients with metal-on-metal hip prostheses. Skeletal Radiol 2014; 43: $1101-1112$

[35] Cho ZH, Kim DJ, Kim YK. Total inhomogeneity correction including chemical shifts and susceptibility by view angle tilting. Med Phys 1988; 15 : $7-11$

[36] Dillenseger JP, Moliere S, Choquet P et al. An illustrative review to understand and manage metal-induced artifacts in musculoskeletal MRI: a primer and updates. Skeletal Radiol 2016; 45: 677-688

[37] Sutter R, Ulbrich EJ, Jellus $V$ et al. Reduction of metal artifacts in patients with total hip arthroplasty with slice-encoding metal artifact correction and view-angle tilting MR imaging. Radiology 2012; 265: 204-214

[38] Idiyatullin D, Corum C, Park JY et al. Fast and quiet MRI using a swept radiofrequency. J Magn Reson 2006; 181: 342 - 349

[39] Carl M, Koch K, Du J. MR imaging near metal with undersampled 3D radial UTE-MAVRIC sequences. Magn Reson Med 2013; 69: 27 - 36

[40] Fritz J, Ahlawat S, Demehri S et al. Compressed Sensing SEMAC: 8-fold Accelerated High Resolution Metal Artifact Reduction MRI of CobaltChromium Knee Arthroplasty Implants. Invest Radiol 2016; 51: 666 676

[41] Filli L, Jud L, Luechinger R et al. Material-Dependent Implant Artifact Reduction Using SEMAC-VAT and MAVRIC: A Prospective MRI Phantom Study. Invest Radiol 2017. doi:10.1097/RLI.0000000000000351

[42] Frisch NB, Wessell NM, Taliaferro $\mathrm{K}$ et al. Ultrasound findings in asymptomatic patients with modular metal on metal total hip arthroplasty. Skeletal Radiol 2017; 46: 641-649

[43] Muraoka K, Naito M, Nakamura Y et al. Usefulness of ultrasonography for detection of pseudotumors after metal-on-metal total hip arthroplasty. J Arthroplasty 2015; 30: 879-884

[44] Garbuz DS, Hargreaves BA, Duncan CP et al. The John Charnley Award: Diagnostic accuracy of MRI versus ultrasound for detecting pseudotumors in asymptomatic metal-on-metal THA. Clin Orthop Relat Res 2014; 472: $417-423$ 